OPEN ACCESS

Edited by:

Pamela Ann McCombe University of Queensland, Australia

Reviewed by:

Stefan Blum,

University of Queensland, Australia

Todd Hardy

Concord Repatriation General Hospital, Australia

*Correspondence:

Yi Yang

doctoryangyi@163.com

tThese authors have contributed equally to this work

Specialty section:

This article was submitted to

Multiple Sclerosis and

Neuroimmunology,

a section of the journal

Frontiers in Neurology

Received: 22 July 2019 Accepted: 30 October 2019

Published: 13 November 2019

Citation:

Jin H, Qu Y, Guo Z-N, Cui G-Z,

Zhang F-L and Yang $Y$ (2019) Primary Angiitis of the Central Nervous System

Mimicking Glioblastoma: A Case Report and Literature Review.

Front. Neurol. 10:1208.

doi: 10.3389/fneur.2019.01208

\section{Primary Angiitis of the Central Nervous System Mimicking Glioblastoma: A Case Report and Literature Review}

\author{
Hang Jin ${ }^{1 \dagger}$, Yang Qu ${ }^{1 \dagger}$, Zhen-Ni Guo ${ }^{2}$, Guo-Zhen Cui ${ }^{3}$, Fu-Liang Zhang ${ }^{1}$ and Yi Yang ${ }^{1,2 *}$ \\ ${ }^{1}$ Department of Neurology, Stroke Center, The First Hospital of Jilin University, Changchun, China, ${ }^{2}$ Department of \\ Neurology, Clinical Trial and Research Center for Stroke, The First Hospital of Jilin University, Changchun, China, \\ ${ }^{3}$ Department of Hepatology, Cancer Center, The First Hospital of Jilin University, Changchun, China
}

Primary angiitis of the central nervous system (PACNS) is a rare disorder resulting in idiopathic inflammation affecting the parenchymal and leptomeningeal vessels confined to the central nervous system (CNS), of which a tumor-like mass lesion is an even rare subtype. We described a case of PACNS initially misdiagnosed as glioblastoma. The patient was a 35 year-old female with right-sided weakness and expressive dysphasia. Brain MRI showed a tumor-like lesion highly suggestive of glioblastoma, therefor surgical removal was done. After a resection and an exhaustive workup, PACNS was ultimately diagnosed. The case illustrates a type of imaging presentation of PACNS that is often misdiagnosed as high-grade glioma. Differentiation between tumor-like PACNS lesions and actual CNS tumors is challenging due to similar MR images. To avoid unnecessary surgical interventions, we summarized previously reported mass-forming PACNS cases in adults from January 1, 2000, to December 31, 2018 and the imaging characteristics of PACNS. Some less commonly used diagnostic methods such as MR spectroscopy may also help clinicians distinguish PACNS from its mimics.

Keywords: primary angiitis of the central nervous system, tumor-like lesion, vasculitis, imaging diagnosis, malignant glioma

\section{BACKGROUND}

Tumor-like mass lesion is a rare presentation of PACNS, accounting for only $5 \%$ of all PACNS. Accordingly, it is difficult to differentiate tumor-like PACNS from neoplastic diseases. This report describes a patient presenting with a cerebral mass lesion in the left parietal lobe, clinically consistent on initial neuroimaging with high-grade glioma, which was ultimately diagnosed of PACNS by histopathology. PACNS cases with tumor-like lesion similar to the current patient are rare. This report summarizes these cases from January 1, 2000, to December 31, 2018. Additionally, to avoid unnecessary surgical interventions, this report summarizes the imaging characteristics of tumor-like mass lesion in PACNS and some less commonly used diagnostic methods such as MR spectroscopy that may also help clinicians distinguish PACNS from its mimics.

\section{CASE PRESENTATION}

A 35 year-old Chinese woman was admitted to our hospital 2 days after an acute onset of right-sided weakness and expressive dysphasia. She had no history of infection and vaccination within 6 weeks 
and no other medical history. Her family had no hereditary diseases. The patient was a salesclerk in a bookstore. She never drank alcohol or smoked. A systemic examination was unremarkable. A neurological examination revealed motor aphasia, facial asymmetry, 2/5 strength in the right upper and lower extremities, and a positive right-sided Babinski reflex.

A brain MRI showed a tumor-like lesion with surrounding edema in subcortical of the left parietal lobe highly suggestive of glioma. The mass lesion demonstrated hypodensity on the brain MRI T1 image, hyperintensity on the MRI T2 image, and hypointensity on the fluid-attenuated inversion recovery (FLAIR) sequences. A gadolinium-enhanced MRI showed a solitary $2.8 \mathrm{~cm} \times 2.6 \mathrm{~cm} \times 4.1 \mathrm{~cm}$ irregular peripheral enhancement mass with a central non-enhancing area centered in the left parietal lobe (Figures 1A-D). Magnetic resonance angiography displayed mildly abnormal with no sign of vasculitis; slight narrowing was observed in the bilateral siphon carotid arteries, bilateral anterior cerebral arteries, and the M1 segment of the left middle cerebral artery. All of the preoperative laboratory findings were within the normal limits: white blood cells were $8.76 \times 10^{9} / \mathrm{L}$ (normal, 4.0-10.0), red blood cells were $3.93 \times 10^{12} / \mathrm{L}$ (normal, 3.5-5.1), hemoglobin was 116 $\mathrm{g} / \mathrm{L}$ (normal, 115-150), and hematocrit was 0.361 (normal, $0.350-0.450$ ). Electrolytes with glucose level, liver function test, arterial blood gas, renal function test, and thyroid function test were within the normal limits. The venereal disease research laboratory (VDRL) test was non-reactive. High-grade glioma was provisionally diagnosed and the patient underwent a mass resection. However, the histopathological examinations revealed a lymphocytic inflammatory infiltrate in the vessel walls and perivascular zones, and parts of the vessels demonstrated necrotic wall damage and contained hyaline microthrombi, consistent with central nervous system vasculitis (Figure 2). Immunohistochemical examinations showed negative staining for Ki-67, P53, GFAP, IDH1, R132H, 01igo-2, MBP, Map2, NeuN, Syn, and CD68. After surgery, the patient's consciousness deteriorated, and a postoperative MRI scan demonstrated flaky extensive perifocal edema that could not be explained by glioma (Figures 1E-H).

Once vasculitis was diagnosed, an evaluation of its secondary causes was pursued. Acute phase reactants, for example, the erythrocyte sedimentation rate (ESR) and C-reactive protein (CRP), and a complete blood count (CBC) were normal. Serum antineutrophil cytoplasmic antibody (ANCA), antinuclear antibodies (ANAs), anticardiolipin antibody (ACA), antidoublestranded DNA, rheumatoid factor (RF), cyclic citrullinated peptide (CCP), complement 3 and 4, immunoglobulin G ( $\operatorname{IgG}), \operatorname{IgM}$, and $\operatorname{IgA}$ remained within the normal ranges. Whole-body fluorodeoxyglucose-PET (FDG-PET) and several serum tumor markers (CA724, CYFRA21-1, CEA, CA242, CA125, NSE, AFP, SCC, CA199, CA153, HCG) suggested no evidence of metastatic tumors. Lumbar puncture showed the patient's intracranial pressure was $390 \mathrm{~cm} \mathrm{H}_{2} \mathrm{O}$ (normal range, 80-180) and a cerebrospinal fluid analysis identified lymphocytic predominant pleocytosis $\left(64 \times 10^{6}\right.$ cells/L, local reference range, $\left.0-8 \times 10^{6}\right)$, elevated protein $(0.82$ $\mathrm{g} / \mathrm{L}$, local reference range, $0.15-0.45)$, and normal glucose levels $(3.40 \mathrm{mmol} / \mathrm{L}$, normal range, 2.3-4.1). Other CSF findings included IgG (39.00 mg/L, normal range, $0-34), \operatorname{IgG}$ index $(3.63$, normal < 0.85), IgG synthesis $(151.2 \mathrm{mg} / 24 \mathrm{~h}$, normal < 7.0), and oligoclonal bands (positive, normal negative). The results of cytologic studies and bacterial and viral cultures were all negative. Additional testing of the CSF and serum including antibodies in various paraneoplastic neurological syndromes, myelin basic protein (MBP), MBP antibody (MBP-Ab), myelin oligodendrocyte glycoprotein antibody (MOG-Ab), and aquaporin 4 antibody (AQP4-Ab) were all within the normal ranges. Further examinations revealed no evidence of metabolic, autoimmune, or infectious disorders, systemic vasculitis, or neoplastic malignancy. PACNS was diagnosed.

The patient was commenced on intravenous methylprednisolone $1 \mathrm{~g}$ daily, halved every 3 days and tapered over 12 days to prednisone $60 \mathrm{mg}$ daily via oral administration with $2.5 \mathrm{mg} /$ week reduction, and the treatment was maintained for approximately 6 months. A repeat brain MRI after 6 months of treatment showed that the lesion had nearly disappeared with the resolution of edema and mass effect (Figures 1I-L). At a 1 year follow-up, the patient could walk independently.

\section{DISCUSSION}

Many inflammatory and infectious processes affect the central nervous system (CNS) and can simulate other neurosurgical pathologies (1). This report describes a peculiar case of histopathologically proven PACNS presenting a tumor-like lesion, which was initially misdiagnosed as malignant glioma, and surgical removal was done unnecessarily. This study also summarizes the imaging characteristics of tumor-like mass lesion PACNS to possibly avoid unnecessary surgical interventions.

PACNS, also known as primary central nervous system vasculitis (PCNSV), is a rare disorder resulting in idiopathic inflammation affecting the parenchymal and leptomeningeal vessels confined to the CNS (2). Secondary causes of vasculitis should be ruled out via thorough clinical and laboratory examinations (3). This disorder was first considered a distinct clinical entity in 1959 by Cravioto and Feigin (4). In 1988, Calabrese and Mallek systematically reported eight cases of this disease, named it PACNS, and proposed the preliminary clinical criteria for diagnosis (3). Supplementary clinical diagnoses were proposed by Birnbaum and Hellmann (5). In 2011, Hajj-Ali et al. proposed classification criteria based on clinical manifestations, imaging results, and pathological biopsy findings in brain tissue (6).

PACNS remains a rare disorder. A retrospective analysis of 163 cases from the Mayo Clinic (Rochester, MN, USA) over a 29 year period from 1983 to 2011 revealed that the average annual incidence rate of PACNS was 2.4 cases per 1 million personyears (7). The disease was more common in males. In the Mayo Clinic sample, the male-female ratio was $\sim 0.8$ to 1 (7). PACNS may occur at almost any age. Approximately $50 \%$ of patients are between 40 and 60 years old. The condition is very uncommon in children (8). 


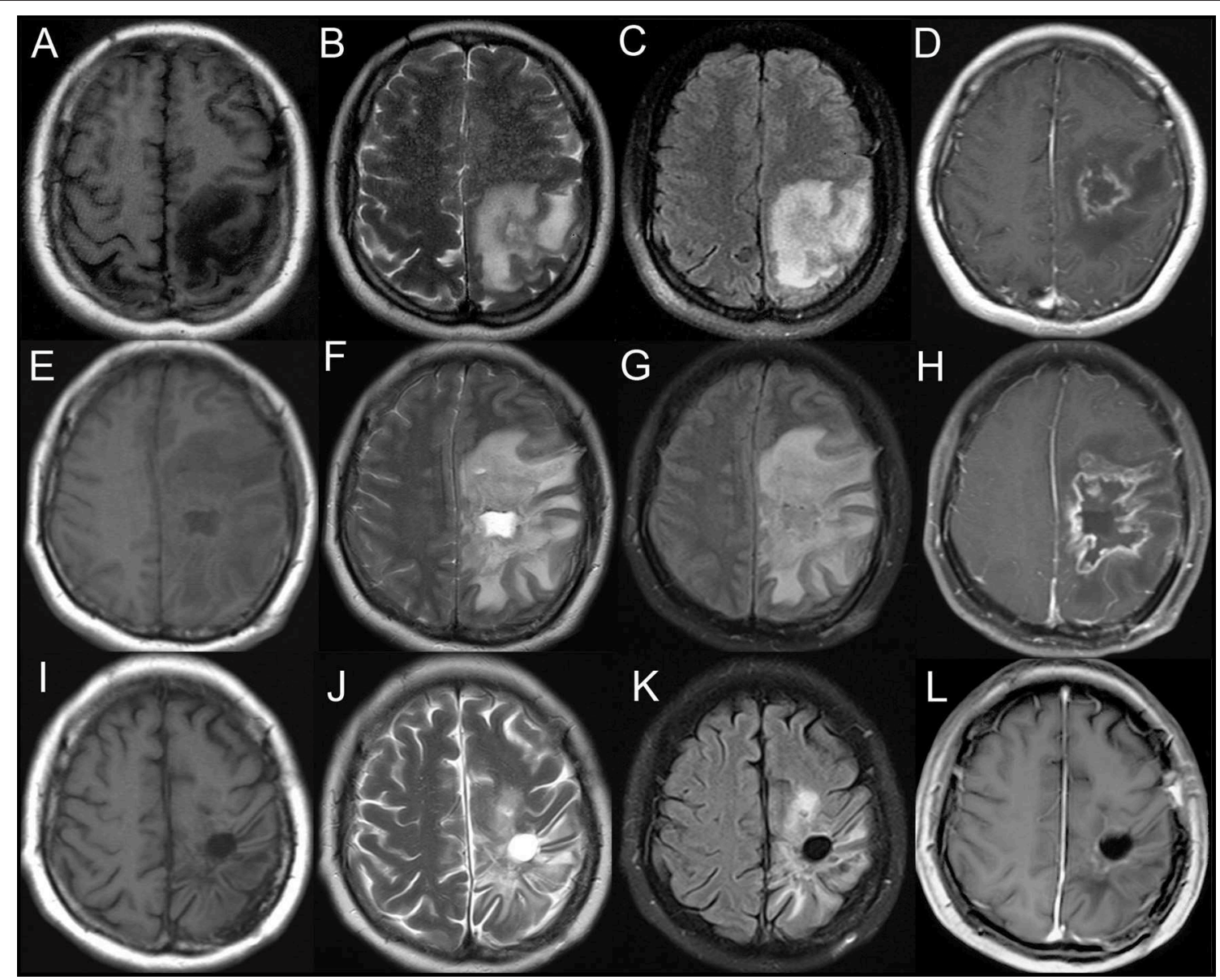

FIGURE 1 | Axial T1-weighted (A), T2-weighted (B), and fluid-attenuated inversion recovery (FLAIR) (C) demonstrating a heterogeneous mass centered in the left parietal lobe. T1-weighted gadolinium-enhanced (D) MRI showing an irregular peripheral enhancement mass with a central non-enhancing area. (E-H) Postoperative MRI scan showing a flaky edema area in the left frontotemporal lobe. Axial T1-weighted (I), T2-weighted (J), fluid-attenuated inversion recovery (FLAIR) (K), and T1-weighted gadolinium-enhanced (L) MRI showing no evidence of contrast enhancement in the left parietal lobe on 6 month follow-up.

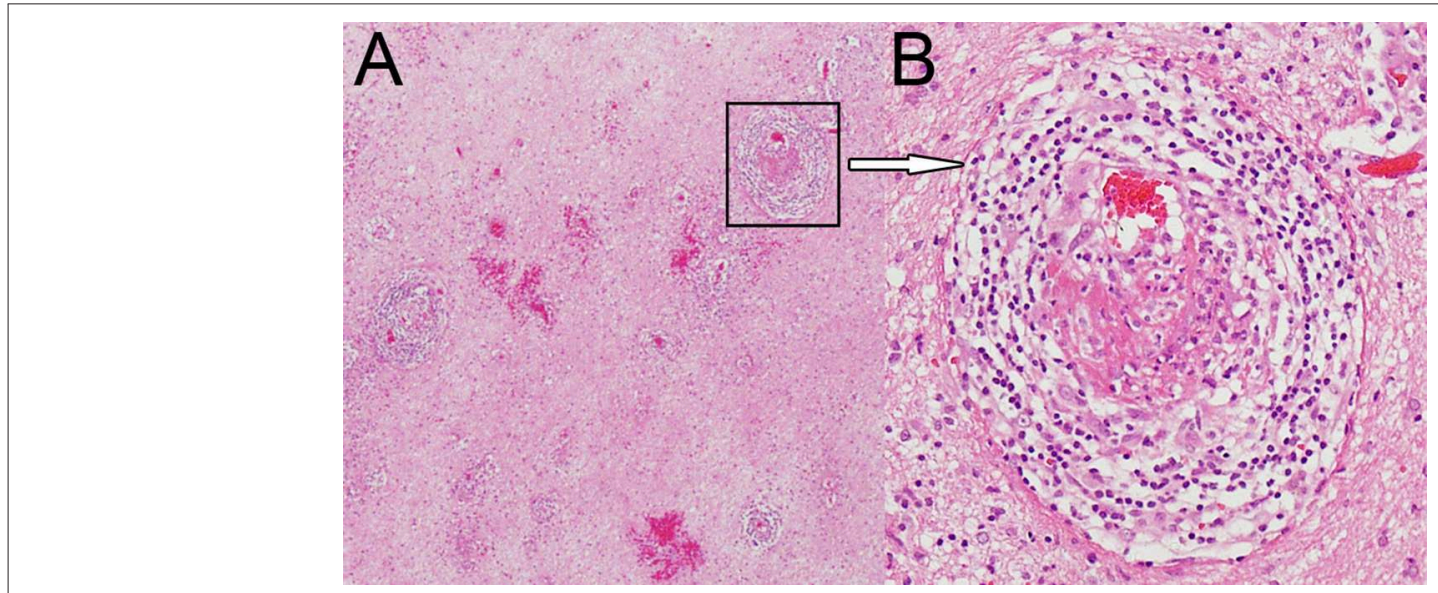

FIGURE 2 | Hematoxylin and eosin staining magnified 40× (A) and 200× (B) showing dense perivascular lymphohistiocytic infiltration. 
Major symptoms of PACNS at diagnosis are highly variable and non-specific, including headache (60\%), altered cognition (50\%), and focal neurologic deficits or stroke (for example, hemiparesis, ataxia, aphasia, dysarthria, and visual disturbances) $(9,10)$. These manifestations are also the initial symptoms in twothirds or more of cases. The onset may be abrupt but is usually gradual and progressive (8). Less common presenting symptoms include seizures, ataxia, coma, and cranial neuropathies (11).

The results of serum and CSF tests are usually normal, which mainly helps to exclude other possible causes of the symptoms (7). A minority of PACNS patients may have mildly elevated acute-phase reactants such as ESR and CPR (7, 12-14). A previous study reported that the clinical findings and outcomes in patients with elevated ESR did not differ from those with normal ESR (7). If other serological findings including ANCA, ANAs, ACA, antidouble-stranded DNA, RF, and complement 3 and 4 are obviously abnormal, secondary factors of vasculitis should be considered. CSF findings are necessary but are generally mild and non-specific. Changes typically consisted of lymphocytic pleocytosis, increased total protein concentrations, and normal glucose levels, parallel with the results of aseptic meningitis, and occasionally with the presence of oligoclonal bands and elevated IgG synthesis $(7,15)$. Infectious disorder, systemic vasculitides, and neoplastic malignancy were excluded in our patient according to her serum and CSF tests, but she was also part of a small group with positive oligoclonal bands and elevated IgG synthesis.

PACNS imaging methods can be divided into three categories based on the structures examined (16), of which MRI is the most common choice in practice (17). MRI findings of PACNS are sensitive but non-specific, and several studies have reported an MRI sensitivity $\sim 90-100 \%(7,14)$. A wide variety of brain MRI changes occur in PACNS, and 10 of the most common have been listed (18). Most PACNS symptoms present as multiple bilateral asymmetrical segmental inflammation of the small and medium vessels of the CNS (19). However, only 5\% of PACNS cases present tumor-like mass lesions (2). One of the mechanisms of the formation of a mass lesion is a breakdown of the blood-brain barrier of the small vessels via the infiltration of inflammatory cells in the perivascular and parenchymal regions, resulting in a mass-mimicking enhanced lesion (20). Amyloid angiopathy may also play a part (21). In the present case, the postsurgical flaky extensive perifocal edema was thought to be associated with vascular and perivascular inflammatory changes.

The solitary tumor-like mass lesions of PACNS are rare, which usually show high signal intensity on T2 and heterogeneously enhancing signals on Gd-enhanced images (17, 22-26). Previously reported mass-forming PACNS cases in adults from 2000 to the present are summarized in the Table 1. Most PACNS lesions occur in the supratentorial subcortical and deep white matter similar to the present patient. However, Zhang et al. (20) reported that the first case of PACNS occurring in the cerebellum was initially misdiagnosed as a malignant glioma, and the mass was unnecessarily resected via a retrosigmoid approach. Lee et al. (26) reported another case that manifested as a suprasellar mass, the preoperative diagnosis of which was a malignant tumor. Another case of PACNS that mimicked a malignant brainstem neoplasm disseminating into the ventricles and cervical spinal cord was reported in 2008, unfortunately, the patient died of respiratory dysfunction 2 weeks later (31).

The present patient had a single, tumor-like enhancing lesion associated with extensive vasogenic edema on MR imaging. Conversely, PACNS presenting multiple lesions that also mimic aggressive multifocal cerebral neoplasm have been reported (26, 31-34). A retrospective study of 10 tumor-like PACNS cases in France found that the number of patients with single and multiple lesions was similar (4 and 3 patients, respectively) (35). The Mayo Clinic analysis showed that nearly $83 \%$ of the multiple lesions tended to be bilateral (7). Panchal et al. (33) and Michael et al. (36) reported cases in which all of the multiple lesions were confined to one cerebral hemisphere, while the other cerebral hemisphere, cerebellum, and brain stem were completely normal. After the initiation of appropriate therapy, both patients had rapid improvement clinically and on MR imaging.

Studies of the vessel lumen include digital subtraction cerebral angiography (DAS), MRA, computed tomography angiography (CTA), and transcranial doppler (TCD). The sensitivity of these methods is not high, but positive results can be used as evidence for suspected cases of PACNS. When the vessel diameter is $<0.2 \mathrm{~mm}$, DSA, currently the superior imaging technique, is often negative. When large blood vessels are involved, especially if the changes are present bilaterally and in multiple arteries, they often show alternating segments of stenosis, referred to as beading, and normal or dilated segments and arterial occlusions $(8,37,38)$.

Differentiation between tumor-like PACNS lesions and actual CNS tumors is challenging because of similar MR patterns. The diagnosis is essential for medical intervention strategies because the treatment of these two types of diseases is completely different. If untreated, patients with PACNS will deteriorate rapidly. Early recognition and therapy may help improve outcomes in patients with PACNS. However, the current diagnostic methods lack specificity, and some seldom-used methods may help clinicians distinguish them.

MR spectroscopy may be very beneficial for the evaluation of patients presenting with tumefactive lesions of the CNS. Typical findings in glioma include high choline, low $\mathrm{N}$-acetyl-aspartate (NAA) peaks, and high lactate levels (23). Elevated glutamate and/or glutamine peaks were observed in three case reports, the local accumulation of which was due to the breakdown of both neural and glial elements and the associated adjacent astrocytic response under inflammatory conditions $(25,33,39)$. Elevation of these peaks may suggest an inflammatory etiology even if the imaging pattern is more consistent with a neoplastic disorder. Researchers also observed elevated choline/NAA ratios and lipid/lactate peaks to varying degrees. Nonspecific findings were observed in the degree of choline, NAA peaks, and lactate levels $(20,26,33,39)$. Furthermore, the fractional anisotropy (FA) values on DT imaging in a case reported in 2007 were very low in both the peripheral enhancing region and the central necrotic region, which tend to be high for tumors classified as high-grade gliomas $(40,41)$. This finding enabled us to eliminate a glioblastoma diagnosis and may develop into a new method of identification of PACNS after further study in a 
TABLE 1 | Summary of PACNS with a tumor-like lesion in adult patients from January 1, 2000, to December 31, 2018

\begin{tabular}{|c|c|c|c|c|c|c|c|c|c|}
\hline References & $\begin{array}{l}\text { Age at diagnosis } \\
\text { (years) and } \\
\text { gender }\end{array}$ & $\begin{array}{l}\text { Clinical } \\
\text { presentation }\end{array}$ & $\begin{array}{l}\text { Laboratory } \\
\text { findings }\end{array}$ & CSF analysis & $\begin{array}{l}\text { Type of } \\
\text { vasculitis }\end{array}$ & MRI brain results & Location & Treatment & Outcome \\
\hline Molloy et al. (2) & $43 \mathrm{~F}$ & $\begin{array}{l}\text { Reduced coordination } \\
\text { and visuospatial } \\
\text { disorientation with right } \\
\text { inferior quadrantanopia }\end{array}$ & Not mentioned & Not mentioned & Lymphocytic & $\begin{array}{l}\text { A large contrast } \\
\text { enhancing mass with } \\
\text { edema and local mass } \\
\text { effect }\end{array}$ & $\begin{array}{l}\text { The left parietal } \\
\text { lobe }\end{array}$ & $\begin{array}{l}\text { Surgical removal, } \\
\text { glucocorticoids, and } \\
\text { mycophenolate mofetil }\end{array}$ & $\begin{array}{l}\text { No recurrence on } 21 \\
\text { month follow up }\end{array}$ \\
\hline Lee et al. (26) & $24 \mathrm{M}$ & Seizure & Not mentioned & Not mentioned & Lymphocytic & $\begin{array}{l}\text { High signal on } \mathrm{T} 2 \text {, low } \\
\text { signal on } \mathrm{T} 1 \text {, increased } \\
\mathrm{ADC} \text {, normal angiogram }\end{array}$ & $\begin{array}{l}\text { The left frontal } \\
\text { lobe }\end{array}$ & $\begin{array}{l}\text { Corticosteroids and } \\
\text { lesionectomy }\end{array}$ & $\begin{array}{l}\text { Disappeared } \\
\text { multiple-enhancing } \\
\text { lesions on } 8.1 \text { year } \\
\text { follow up }\end{array}$ \\
\hline Lee et al. (26) & $37 \mathrm{~F}$ & $\begin{array}{l}\text { Sleeping tendency, } \\
\text { poor oral intake, and } \\
\text { decreased verbal } \\
\text { output }\end{array}$ & Not mentioned & Not mentioned & Lymphocytic & $\begin{array}{l}2.3 \mathrm{~cm} \text { enhancing mass } \\
\text { with edema, decreased } \\
\mathrm{ADC}, \mathrm{MCA} \mathrm{M} 1 \text { occlusion, } \\
\text { and left distal ICA stenosis } \\
\text { on angiogram }\end{array}$ & Suprasellar area & $\begin{array}{l}\text { Cyclophosphamide } \\
\text { and corticosteroids }\end{array}$ & $\begin{array}{l}\text { Decreased size on } 1 \\
\text { year follow up }\end{array}$ \\
\hline You et al. (27) & $35 \mathrm{~F}$ & $\begin{array}{l}\text { Headache and left- } \\
\text { sided weakness }\end{array}$ & Normal & $\begin{array}{l}\text { Increased total protein: } \\
170 \mathrm{mg} / \mathrm{dl} \text {; MBP } 2.23 \\
\mathrm{nmol} / \mathrm{l} \text {; increased lgG in } \\
\mathrm{CSF} \text { index } 20.5 \mathrm{mg} / \mathrm{dl}\end{array}$ & Lymphocytic & $\begin{array}{l}\text { A tumor-like mass with } \\
\text { edema and } \\
\text { enhancement }\end{array}$ & $\begin{array}{l}\text { The right parietal } \\
\text { lobe }\end{array}$ & $\begin{array}{l}\text { Subtotal resection, } \\
\text { prednisolone, and } \\
\text { cyclophosphamide }\end{array}$ & $\begin{array}{l}\text { Neurological } \\
\text { symptoms } \\
\text { disappeared on } 6 \\
\text { week follow up }\end{array}$ \\
\hline Tanei et al. (24) & $60 \mathrm{M}$ & $\begin{array}{l}\text { Slight disorientation, } \\
\text { left hemiparesis, and } \\
\text { motor } \\
\text { aphasia }\end{array}$ & Normal & Normal & Granulomatous & $\begin{array}{l}\text { A slightly enhanced mass } \\
\text { lesion with surrounding } \\
\text { edema }\end{array}$ & $\begin{array}{l}\text { The right parietal } \\
\text { lobe }\end{array}$ & Surgical removal only & $\begin{array}{l}\text { Improvement with } \\
\text { no new lesions on } 6 \\
\text { month follow up }\end{array}$ \\
\hline Muccio et al. (25) & $46 \mathrm{~F}$ & $\begin{array}{l}\text { Progressive confusion, } \\
\text { headache, dizziness, } \\
\text { and nystagmus }\end{array}$ & Not mentioned & Not mentioned & Lymphocytic & $\begin{array}{l}\text { Increased signal on } \\
\text { FLAIR, low signal on T1, } \\
\text { and signal intensification } \\
\text { with contrast }\end{array}$ & $\begin{array}{l}\text { The right temporal } \\
\text { lobe }\end{array}$ & al Steroids & $\begin{array}{l}\text { Regression of the } \\
\text { lesion on } 3 \text { month } \\
\text { follow up }\end{array}$ \\
\hline Pizzanelli et al. (28) & $50 \mathrm{~F}$ & $\begin{array}{l}\text { Speech disorder, } \\
\text { headache, and } \\
\text { apathy }\end{array}$ & Not mentioned & Not mentioned & Lymphocytic & $\begin{array}{l}\text { Mixed hyperintensity on } \\
\text { T2 with conspicuous } \\
\text { edema }\end{array}$ & $\begin{array}{l}\text { The left frontal } \\
\text { lobe }\end{array}$ & $\begin{array}{l}\text { Surgical removal, } \\
\text { steroids, and } \\
\text { cyclophosphamide }\end{array}$ & $\begin{array}{l}\text { Recurrence after } \\
\text { one year and } 5 \\
\text { months }\end{array}$ \\
\hline Killeen et al. (29) & $51 \mathrm{M}$ & $\begin{array}{l}\text { Headache and left } \\
\text { homonymous } \\
\text { hemianopia }\end{array}$ & Normal & $\begin{array}{l}\text { Mononuclear } \\
\text { pleocytosis: 58/L } \\
\text { elevated protein: } 1400 \\
\text { mg/L }\end{array}$ & Lymphohistiocytic & $\begin{array}{l}\text { Extensive perifocal } \\
\text { edema, ring-enhancing } \\
\text { and central necrotic mass } \\
\text { on MRI }\end{array}$ & $\begin{array}{l}\text { The white matter } \\
\text { adjacent to the } \\
\text { posterior horn of } \\
\text { the right lateral } \\
\text { ventricle }\end{array}$ & $\begin{array}{l}\text { Oral prednisolone and } \\
\text { cyclophosphamide }\end{array}$ & $\begin{array}{l}\text { Suffered no } \\
\text { recurrence on } 4 \text { year } \\
\text { follow up }\end{array}$ \\
\hline Kim et al. (22) & $20 \mathrm{~F}$ & $\begin{array}{l}\text { Right facial focal motor } \\
\text { seizures }\end{array}$ & $\begin{array}{l}\text { Elevated CRP: } \\
9.80 \mathrm{mg} / \mathrm{dL}\end{array}$ & Not mentioned & Lymphocytic & $\begin{array}{l}\text { High signal intensity on T2 } \\
\text { and heterogeneous } \\
\text { enhancement with } \\
\text { contrast }\end{array}$ & $\begin{array}{l}\text { The left posterior } \\
\text { frontal area }\end{array}$ & Surgical removal & $\begin{array}{l}\text { No new lesions on } 3 \\
\text { year follow up }\end{array}$ \\
\hline Sun et al. (30) & $42 \mathrm{M}$ & $\begin{array}{l}\text { Headache, convulsions, } \\
\text { and aphasia }\end{array}$ & Not mentioned & Normal & Lymphocytic & $\begin{array}{l}\text { A tumor-like mass with } \\
\text { edema and high signal } \\
\text { intensity on FLAIR }\end{array}$ & $\begin{array}{l}\text { The left } \\
\text { frontotemporal } \\
\text { lobe }\end{array}$ & $\begin{array}{l}\text { Surgical removal, } \\
\text { methylprednisolone, } \\
\text { and subsequent oral } \\
\text { prednisolone }\end{array}$ & $\begin{array}{l}\text { Only aphasia on } 1 \\
\text { year follow up }\end{array}$ \\
\hline
\end{tabular}


limited group of patients (39). Some cases also revealed changes in perfusion MR imaging and CT, even so other studies also described their potential usefulness for diagnosis of vasculitis. When conventional MR imaging and angiography are normal, perfusion imaging may provide information related to focal perfusion abnormality $(25,26)$.

Advances in imaging such as high resolution magnetic resonance imaging (HR-MRI) provide information regarding the vessel lumen and vessel walls, particularly the wall structure of the intracranial blood vessels, which cannot be obtained by luminal imaging $(16,42)$. Thickening of large vessels and extramural enhancement revealed by HR-MRI may be more specific for the diagnosis of PACNS (43) that is not always seen in neoplastic disorders of the CNS. Although to define specificity and the role of HR-MRI in the diagnostic process, further studies of inflammatory and non-inflammatory vascular disorders are needed (6), HR-MRI can also be used to distinguish tumor-like lesion PACNS and high-grade glioma.

To date, brain biopsy remains the gold standard for the diagnosis of PACNS. Special stains and cultures of pathologic samples are essential to confirm that the lesions do not represent a secondary form of vasculitis. Immunohistochemistry and molecular analysis of T-cell and B-cell clonality should also be considered to exclude CNS lymphoma, a common mimic of PACNS $(6,15)$. Histological findings in PACNS commonly include a lymphocytic inflammatory reaction with variable numbers of plasma cells, histiocytes, neutrophils, and eosinophils (11). A study showed that $89 \%$ of PACNS patients with tumor-like lesions presented lymphocytic patterns, similar to other PACNS subtypes. Granulomatous patterns were next, accounting for approximately 14\% (35). Unfortunately, immunohistochemistry and molecular analysis of T-cell and Bcell clonality was not completed in our patient because our neurosurgeons did not doubt the diagnosis of the patient's glioma before surgery. Although glucocorticoid therapy was effective cannot exclude CNS lymphoma, hypermetabolic lesions of the CNS were not found in FDG-PET (44), so CNS lymphoma can also be excluded. Tumefactive demylanting lesions (TDLs), another common mimic of PACNS also need pathologic examination to distinguish. For our patient, according to initial the MRI appearance, TDLs should be considered. It is histological examination that help us to make a clear diagnosis (45).

Of note, after the initiation of therapy, there was a rapid improvement both clinically and on MR imaging in the present case. However, an analysis revealed that for tumor-like PACNS patients, outcomes were favorable in cases involving a combination of glucocorticoids and cyclophosphamide compared to those treated with glucocorticoids alone (35).

\section{CONCLUSIONS}

Tumor-like PACNS cases are rare. Such patients are often misdiagnosed with high-grade gliomas because of T1-weighted low signal intensity, T2-weighted high signal intensity, gadolinium enhancement, and significant edema and mass effect. Preoperative radiological evaluation may not always 
directly provide the exact diagnosis. Brain biopsy is the gold standard diagnosis, but this is an invasive test accompanied with a small but significant risk of serious complications. Imaging procedures may be a key part of the workup of patients with PACNS. Some uncommonly used methods such as MR spectroscopy may help clinicians distinguish PACNS from its mimics. Furthermore, early combined therapy with aggressive immunosuppressants and steroids may help improve outcomes in PACNS patients.

\section{ETHICS STATEMENT}

This study was carried out in accordance with the recommendations of the Human and Research Ethics committees of the First Hospital of Jilin University with written informed consent from the patient. The patient gave

\section{REFERENCES}

1. Rapalino O, Mullins ME. Intracranial infectious and inflammatory diseases presenting as neurosurgical pathologies. Neurosurgery. (2017) 81:10-28. doi: 10.1093/neuros/nyx201

2. Molloy ES, Singhal AB, Calabrese LH. Tumour-like mass lesion: an underrecognised presentation of primary angiitis of the central nervous system. Ann Rheum Dis. (2008) 67:1732-5. doi: 10.1136/ard.2008.096800

3. Calabrese LH, Mallek JA. Primary angiitis of the central nervous system. Report of 8 new cases, review of the literature, and proposal for diagnostic criteria. Medicine. (1988) 67:20-39. doi: 10.1097/00005792-198801000-00002

4. Cravioto H, Feigin I. Noninfectious granulomatous angiitis with a predilection for the nervous system. Neurology. (1959) 9:599-609. doi: 10.1212/WNL.9.9.599

5. Birnbaum J, Hellmann DB. Primary angiitis of the central nervous system. Arch Neurol. (2009) 66:704-9. doi: 10.1001/archneurol.2009.76

6. Hajj-Ali RA, Singhal AB, Benseler S, Molloy E, Calabrese LH. Primary angiitis of the CNS. Lancet Neurol. (2011) 10:561-72. doi: 10.1016/S1474-4422(11)70081-3

7. Salvarani C, Brown RD Jr, Christianson T, Miller DV, Giannini C, Huston J, III, et al. An update of the Mayo Clinic cohort of patients with adult primary central nervous system vasculitis: description of 163 patients. Medicine. (2015) 94:e738. doi: 10.1097/MD.0000000000000738

8. Giannini C, Salvarani C, Hunder G, Brown RD. Primary central nervous system vasculitis: pathology and mechanisms. Acta Neuropathol. (2012) 123:759-72. doi: 10.1007/s00401-012-0973-9

9. Kraemer M, Berlit P. Primary central nervous system vasculitis: clinical experiences with 21 new European cases. Rheumatol Int. (2011) 31:463-72. doi: 10.1007/s00296-009-1312-x

10. Berlit P, Kraemer M. Cerebral vasculitis in adults: what are the steps in order to establish the diagnosis? Red flags and pitfalls. Clin Exp Immunol. (2014) 175:419-24. doi: 10.1111/cei.12221

11. Hajj-Ali RA, Calabrese LH. Diagnosis and classification of central nervous system vasculitis. J Autoimmun. (2014) 48-49:149-52. doi: 10.1016/j.jaut.2014.01.007

12. Salvarani C, Brown RD Jr, Calamia KT, Christianson TJ, Weigand SD, Miller DV, et al. Primary central nervous system vasculitis: analysis of 101 patients. Ann Neurol. (2007) 62:442-51. doi: 10.1002/ana.21226

13. Salvarani C, Brown RD, Hunder GG. Adult primary central nervous system vasculitis. Lancet. (2012) 380:767-77. doi: 10.1016/S0140-6736(12)60069-5

14. de Boysson H, Zuber M, Naggara O, Neau JP, Gray F, Bousser MG, et al. Primary angiitis of the central nervous system: description of the first fiftytwo adults enrolled in the French cohort of patients with primary vasculitis of the central nervous system. Arthritis Rheumatol. (2014) 66:1315-26. doi: $10.1002 /$ art. 38340 written informed consent in accordance with the Declaration of Helsinki. Written informed consent was obtained from the patient for the publication of this case report. The protocol was approved by the Human and Research Ethics committees of the First Hospital of Jilin University.

\section{AUTHOR CONTRIBUTIONS}

HJ, YQ, and F-LZ: drafted the manuscript. YQ: acquisition of data. HJ, Z-NG, G-ZC, and F-LZ: analysis or interpretation of data. YY: study concept and design.

\section{FUNDING}

This project was supported by the National Key R\&D Program of China (2016YFC1301600) and JLUSTIRT (2017TD-12) to YY.

15. Hajj-Ali RA, Calabrese LH. Primary angiitis of the central nervous system. Autoimmun Rev. (2013) 12:463-6. doi: 10.1016/j.autrev.2012.08.004

16. Gomes LJ. The role of imaging in the diagnosis of central nervous system vasculitis. Curr Allergy Asthma Rep. (2010) 10:163-70. doi: 10.1007/s11882-010-0102-6

17. Zhu DS, Yang XL, Lv HH, Bai CG, Yang PP, Li ZZ, et al. Seizure syndrome as a first manifestation of solitary tumor-like mass lesion of PACNS: Two case reports. Medicine. (2017) 96:e6018. doi: 10.1097/MD.0000000000006018

18. Powers WJ. Primary angiitis of the central nervous system: diagnostic criteria. Neurol Clin. (2015) 33:515-26. doi: 10.1016/j.ncl.2014.12.004

19. Campi A, Benndorf G, Filippi M, Reganati P, Martinelli V, Terreni MR. Primary angiitis of the central nervous system: serial MRI of brain and spinal cord. Neuroradiology. (2001) 43:599-607. doi: 10.1007/s002340100561

20. Zhang G, Yang C, Chang J, Yuan X, Bai Y, Niu J, et al. Primary angiitis of the central nervous system mimicking a cerebellar tumor. Br J Neurosurg. (2018) 14:1-3. doi: 10.1080/02688697.2018.1464122

21. Tamargo RJ, Connolly ES, McKhann GM, Khandji A, Chang Y, Libien J, et al. Clinicopathological review: primary angiitis of the central nervous system in association with cerebral amyloid angiopathy. Neurosurgery. (2003) 53:136-43. doi: 10.1227/01.NEU.0000068864.20655.31

22. Kim SI, Kim SH, Cho HJ, Kim H, Chung CK, Choi SH, et al. Mass-forming primary angiitis of central nervous system with Rosai-Dorfmann diseaselike massive histiocytosis with emperipolesis. Pathol Int. (2015) 65:420-5. doi: $10.1111 /$ pin. 12317

23. Gan C, Maingard J, Giles L, Phal PM, Tan KM. Primary angiitis of the central nervous system presenting as a mass lesion. J Clin Neurosci. (2015) 22:1528-31. doi: 10.1016/j.jocn.2015.03.030

24. Tanei T, Nakahara N, Takebayashi S, Ito M, Hashizume Y, Wakabayashi T. Primary angiitis of the central nervous system mimicking tumor-like lesion-case report. Neurol Med Chir. (2011) 51:56-9. doi: 10.2176/nmc.51.56

25. Muccio CF, Di Blasi A, Esposito G, Brunese L, D’Arco F, Caranci F. Perfusion and spectroscopy magnetic resonance imaging in a case of lymphocytic vasculitis mimicking brain tumor. Pol J Radiol. (2013) 78:66-9. doi: 10.12659/PJR.884011

26. Lee Y, Kim JH, Kim E, Park SH, Yim YJ, Sohn CH, et al. Tumor-mimicking primary angiitis of the central nervous system: initial and follow-up MR features. Neuroradiology. (2009) 51:651-9. doi: 10.1007/s00234-009-0546-3

27. You G, Yan W, Zhang W, Li S, Li G, Jiang T. Isolated angiitis of the central nervous system with tumor-like lesion, mimicking brain malignant glioma: a case report and review of the literature. World J Surg Oncol. (2011) 9:97. doi: 10.1186/1477-7819-9-97

28. Pizzanelli C, Tavoni A, Pelliccia V, Catarsi E, Pesaresi I, Caltran E, et al. Multiple life-threatening relapses in a woman with primary angiitis of the central nervous system mimicking brain tumour: a case report. Clin Exp Rheumatol. (2014) 32(Suppl. 82):S143-4. 
29. Killeen T, Jucker D, Went P, Muthurajah V, Woon K, Cesnulis E, et al. Solitary tumour-like mass lesions of the central nervous system: primary angiitis of the CNS and inflammatory pseudotumour. Clin Neurol Neurosurg. (2015) 135:34-7. doi: 10.1016/j.clineuro.2015. 05.008

30. Sun LI, Zhu L, Zhao T, Wang D, Ma D, Zhang R, et al. A rare case of tumormimicking primary angiitis of the central nervous system. Mol Clin Oncol. (2016) 4:827-9. doi: 10.3892/mco.2016.784

31. Nabika S, Kiya K, Satoh H, Mizoue T, Araki H, Oshita J, et al. Primary angiitis of the central nervous system mimicking dissemination from brainstem neoplasm: a case report. Surg Neurol. (2008) 70:182-5. doi: 10.1016/j.surneu.2007.05.008

32. Krummert B, Scherer K, Whitley J, Sirelkhatim A, Panda M. A rare cause of seizure masquerading as neoplasm. BMJ Case Rep. (2010) 2010:bcr0720103133. doi: 10.1136/bcr.07.2010.3133

33. Panchal NJ, Niku S, Imbesi SG. Lymphocytic vasculitis mimicking aggressive multifocal cerebral neoplasm: $\mathrm{mr}$ imaging and MR spectroscopic appearance. Am J Neuroradiol. (2005) 26:642-5.

34. Ishikawa E, Tsuboi K, Takano S, Kimura H, Aoki T, Mashiko R, et al. Primary cerebral angiitis containing marked xanthoma cells with massive intraparenchymal involvement-case report. Neurol Med Chir. (2005) 45:15660. doi: $10.2176 /$ nmc. 45.156

35. de Boysson H, Boulouis G, Dequatre N, Godard S, Neel A, Arquizan C, et al. Tumor-like presentation of primary angiitis of the central nervous system. Stroke. (2016) 47:2401-4. doi: 10.1161/STROKEAHA.116.013917

36. Ho MG, Chai W, Vinters HV, Hathout G, Mishra S, Yim C, et al. Unilateral hemispheric primary angiitis of the central nervous system. J Neurol. (2011) 258:1714-6. doi: 10.1007/s00415-0115993-1

37. Zuccoli G, Pipitone N, Haldipur A, Brown RD, Jr, Hunder G, Salvarani C. Imaging findings in primary central nervous system vasculitis. Clin Exp Rheumatol. (2011) 29(Suppl. 64):S104-9.

38. Bai HX, Zou Y, Lee AM, Lancaster E, Yang L. Diagnostic value and safety of brain biopsy in patients with cryptogenic neurological disease: a systematic review and meta-analysis of 831 cases. Neurosurgery. (2015) 77:283-95. doi: 10.1227/NEU.0000000000 000756

39. Beppu T, Inoue T, Nishimoto H, Nakamura S, Nakazato Y, Ogasawara K, et al. Primary granulomatous angiitis of the central nervous system: findings of magnetic resonance spectroscopy and fractional anisotropy in diffusion tensor imaging prior to surgery. Case report. J Neurosurg. (2007) 107:873-7. doi: 10.3171/jns.2007.107.4.873

40. Beppu T, Inoue T, Shibata Y, Kurose A, Arai H, Ogasawara K, et al. Measurement of fractional anisotropy using diffusion tensor MRI in supratentorial astrocytic tumors. J Neurooncol. (2003) 63:109-16. doi: 10.1023/a:1023977520909

41. Goebell E, Paustenbach S, Vaeterlein O, Ding XQ, Heese O, Fiehler $\mathrm{J}$, et al. Low-grade and anaplastic gliomas: differences in architecture evaluated with diffusion-tensor MR imaging. Radiology. (2006) 239:217-22. doi: 10.1148/radiol.2383050059

42. Swartz RH, Bhuta SS, Farb RI, Agid R, Willinsky RA, Terbrugge $\mathrm{KG}$, et al. Intracranial arterial wall imaging using high-resolution 3-tesla contrast-enhanced MRI. Neurology. (2009) 72:627-34. doi: 10.1212/01.wnl.0000342470.69739.b3

43. Noh HJ, Choi JW, Kim JP, Moon GJ, Bang OY. Role of highresolution magnetic resonance imaging in the diagnosis of primary angiitis of the central nervous system. J Clin Neurol. (2014) 10:267-71. doi: 10.3988/jen.2014.10.3.267

44. Zou Y, Tong J, Leng H, Jiang J, Pan M, Chen Z. Diagnostic value of using 18F-FDG PET and PET/CT in immunocompetent patients with primary central nervous system lymphoma: a systematic review and meta-analysis. Oncotarget. (2017) 8:41518-28. doi: 10.18632/oncotarget.17456

45. Tan HM, Chan LL, Chuah KL, Goh NS, Tang KK. Monophasic, solitary tumefactive demyelinating lesion: neuroimaging features and neuropathological diagnosis. $\mathrm{Br} J$ Radiol. (2004) 77:153-6. doi: $10.1259 /$ bjr/26682607

Conflict of Interest: The authors declare that the research was conducted in the absence of any commercial or financial relationships that could be construed as a potential conflict of interest.

Copyright (c) 2019 Jin, Qu, Guo, Cui, Zhang and Yang. This is an open-access article distributed under the terms of the Creative Commons Attribution License (CC BY). The use, distribution or reproduction in other forums is permitted, provided the original author(s) and the copyright owner(s) are credited and that the original publication in this journal is cited, in accordance with accepted academic practice. No use, distribution or reproduction is permitted which does not comply with these terms. 